\title{
Effects of CPAP on oxidative stress and nitrate efficiency in sleep apnoea: a randomised trial
}

\author{
A Alonso-Fernández, ${ }^{1,2}$ F García-Río, ${ }^{3}$ M A Arias, ${ }^{4}$ Á Hernanz, ${ }^{5}$ M de la Peña, ${ }^{1,2}$ \\ J Piérola, ${ }^{6,2}$ A Barceló, ${ }^{7,2}$ E López-Collazo, ${ }^{8,2}$ A Agustí1,8,9
}

${ }^{1}$ Department of Pneumology, Hospital Universitario Son Dureta, Palma de Mallorca, Spain; ${ }^{2}$ CIBER Enfermedades Respiratorias, Palma de Mallorca, Spain; ${ }^{3}$ Department of Pneumology, Hospital Universitario La Paz, Madrid, Spain; ${ }^{4}$ Department of Cardiology, Hospital Virgen de la Salud, Toledo, Spain;

${ }^{5}$ Department of Biochemistry and Molecular Biology, Hospital Universitario La Paz, Madrid,

Spain; ${ }^{6}$ Investigation Unit, Hospital Universitario Son Dureta, Palma de Mallorca, Spain; ${ }^{7}$ Department of Clinical Analysis, Hospital Universitario Son Dureta, Palma de Mallorca, Spain; ${ }^{8}$ Research Unit,

Laboratory of Tumor Immunology, Hospital Universitario La Paz, Madrid, Spain; ${ }^{9}$ Fundación CaubetCIMERA Islas Baleares. International Centre for Advanced Respiratory Medicine, Bunyola, Mallorca, Spain

Correspondence to: Dr A Alonso-Fernández, Servicio de Neumología, Hospital Universitario Son Dureta, C/ Andrea Doria 55, 07014 Palma de Mallorca, Spain; alberto.alonso@ssib.es

Received 5 May 2008 Accepted 20 November 2008 Published Online First 14 December 2008

\begin{abstract}
Background: Previous studies have presented contradictory data concerning obstructive sleep apnoea syndrome (OSAS), lipid oxidation and nitric oxide (NO) bioavailability. This study was undertaken to (1) compare the concentration of 8-isoprostane and total nitrate and nitrite (NOX) in plasma of middle-aged men with OSAS and no other known co-morbidity and healthy controls of the same age, gender and body mass index; and (2) test the hypothesis that nasal continuous positive airway pressure (CPAP) therapy attenuates oxidative stress and nitrate deficiency.

Methods: A prospective, randomised, placebo controlled, double-blind, crossover study was performed in 31 consecutive middle-aged men with newly diagnosed OSAS and 15 healthy control subjects. Patients with OSAS were randomised to receive sham CPAP or effective CPAP for 12 weeks. Blood pressure, urinary catecholamine levels and plasma 8-isoprostane and NOx concentrations were obtained before and after both treatment modalities.
\end{abstract}

Results: Patients with OSAS had significantly higher 8isoprostane levels (median (IQR) 42.5 (29.2-78.2) vs 20.0 (12.5-52.5) pg/ml, $\mathrm{p}=0.041$, Mann-Whitney test) and lower NOx levels (264 (165-650) vs 590 (251-

1465) $\mu \mathrm{mol} / \mathrm{l}, \mathrm{p}=0.022$ ) than healthy subjects. Body mass index, blood pressure and urinary catecholamines were unchanged by CPAP therapy, but 8-isoprostane concentrations decreased (38.5 (24.2-58.7) pg/ml at baseline vs 22.5 (16.2-35.3) pg/ml on CPAP, $p=0.0001)$ and NOx levels increased (280 (177-707) vs 1373 (981-1517) $\mu \mathrm{mol} / \mathrm{l}, \mathrm{p}=0.0001$ ) after CPAP.

Conclusions: OSAS is associated with an increase in oxidative stress and a decrease in NOx that is normalised by CPAP therapy.

Cardiovascular morbidity and mortality is increased in patients with obstructive sleep apnoea syndrome (OSAS). ${ }^{1-6}$ Oxidative and nitrosative stress are believed to contribute to this association $^{7-9}$ because markers of lipid peroxidation appear to be increased in the plasma, exhaled breath condensate and urine of these patients. ${ }^{10-14}$ However, not all studies have been able to replicate these observations. ${ }^{15-17}$ Potential confounding factors explaining this discrepancy may include age differences between patients and controls, the smoking history of the patients and/or the presence of co-morbidities such as obesity, chronic obstructive pulmonary disease (COPD) or cardiovascular disease, all of which are common in OSAS and can be associated with oxidative stress by themselves. ${ }^{245}$ The effect of continuous positive airway pressure (CPAP) therapy on these biological abnormalities is also controversial. Whereas some uncontrolled studies have shown that CPAP therapy decreases oxidative stress in these patients, ${ }^{10} 121318-21$ other groups have failed to demonstrate any significant change after CPAP. ${ }^{16} 17$

To address these limitations we designed a prospective, randomised, double-blind, placebo controlled, crossover study that sought to (1) compare the concentration of 8-isoprostane and total nitrate and nitrite (NOx) in plasma of middle-aged men with OSAS in whom lung and cardiovascular diseases were carefully excluded and in healthy controls of the same age, gender and body mass index (BMI); and (2) test the hypothesis that CPAP therapy improves oxidative stress and nitrate deficiency in these patients.

\section{METHODS \\ Subjects}

Thirty-one consecutive newly diagnosed men with OSAS and 15 healthy male volunteers were included in the study. All patients with OSAS fulfilled all the following inclusion criteria: (1) apnoea-hypopnea index (AHI) $\geqslant 10 / \mathrm{h}$; (2) excessive daytime sleepiness defined by an Epworth scale score of $\geqslant 11$ points; and (3) no treatment for OSAS. Inclusion criteria for healthy control subjects were AHI $<5 / h$ and Epworth sleepiness scale $<10$. Exclusion criteria for both study groups were: (1) unwillingness or inability to participate in the study; (2) obstructive or restrictive lung disease as identified by pulmonary function testing; (3) use of cardioactive drugs; (4) cardiac rhythm disturbances, including sinus bradycardia and sinus tachycardia; (5) known arterial hypertension or $24 \mathrm{~h}$ ambulatory blood pressure monitoring (ABPM) showing blood pressure values $\geqslant 135 / 85 \mathrm{~mm} \mathrm{Hg}$; (6) left ventricular ejection fraction $<50 \%$, ischaemic or valve heart disease, hypertrophic, restrictive or infiltrative cardiomyopathy, pericardial disease or stroke by history, physical examination, ECG, chest radiography, conventional exercise stress testing and echocardiography; (7) diabetes mellitus by history or two random blood glucose levels $\geqslant 126 \mathrm{mg} / \mathrm{dl}$; (8) morbid obesity (BMI $>40 \mathrm{~kg} / \mathrm{m}^{2}$ ); and/or (9) daytime hypoxaemia $\left(\mathrm{PaO}_{2}<70 \mathrm{~mm} \mathrm{Hg}\right)$ or hypercapnia $\left(\mathrm{PaCO}_{2}>45 \mathrm{~mm} \mathrm{Hg}\right)$. Other exclusion criteria during the study period were: (1) need to change medication; (2) hospital admission for 10 or more days; and (3) average nightly CPAP usage less than $3.5 \mathrm{~h}$. Control subjects were recruited from a list of healthy subjects from our sanitary area who had had a routine health test in the previous 3 months. We randomly selected a control subject similar in gender, age ( \pm 2 years), weight $( \pm 2 \mathrm{~kg})$ 
Figure 1 Flow chart of study subjects. CPAP, continuous positive airway pressure; OSAS, obstructive sleep apnoea syndrome.

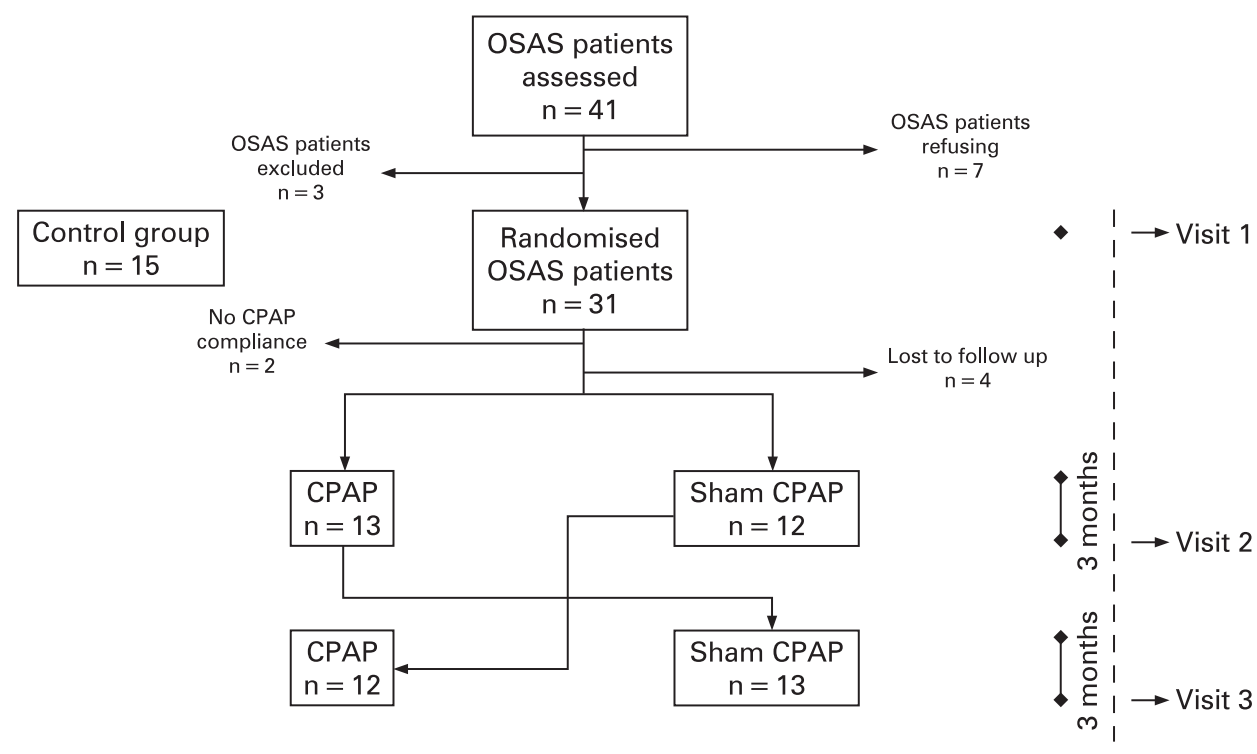

and height $( \pm 5 \mathrm{~cm})$ with regard to the two preceding patients included in the study.

\section{Study design}

A single-centre, prospective, randomised, double-blind, placebo controlled, crossover clinical study was performed in which patients received CPAP and sham therapy ${ }^{22}$ for two 12-week periods. In healthy controls measurements were obtained once. At recruitment, ABPM, echocardiography, catecholamine concentration in urine and a sleep study were undertaken in all participants. After fasting overnight, a venous blood sample (anticoagulated with dipotassium EDTA for determination of 8isoprostane and total nitrate and nitrite ( $\mathrm{NOx}$ ) concentrations) was collected from all participants between 08.00 and $10.00 \mathrm{~h}$. Within $30 \mathrm{~min}$ of blood collection, plasma was obtained by centrifugation at $3000 \mathrm{rpm}$ for $15 \mathrm{~min}$. All plasma samples were stored at $-60^{\circ} \mathrm{C}$ until analysis.

Patients with OSAS underwent a full-night CPAP titration study at home using an automated pressure setting device (Auto Set; ResMed, Sydney, Australia). ${ }^{23}$ Patients were given detailed instructions on the appropriate use of the CPAP equipment and were randomised to receive either effective or sham CPAP therapy for 12 weeks. The sham CPAP device was a modified conventional CPAP device in which the exhalation port diameter had been enlarged to nearly cancel nasal pressure and an orifice resistor was connected between the tubing and the CPAP unit that loads the blower with the same airflow resistance as in effective CPAP. ${ }^{22}$ No information about the type of therapy they were receiving was given. Compliance with therapy was obtained from a built-in run time counter. After 12 weeks the CPAP device was switched to the alternate mode of therapy and ABPM and plasma and urine sampling were repeated (fig 1 ).

\section{Measurements}

A validated portable recording device (Sibel Home-300; Sibel SA, Barcelona, Spain $)^{24}$ that records oronasal airflow using a thermistor and nasal cannula prongs, chest wall impedance, oxygen saturation, snoring and body position was used to perform a sleep study in patients and healthy controls. Respiratory events were classified as either obstructive or central on the basis of the presence or absence of respiratory effort. Respiratory events were scored as apnoeas when there was a cessation of oronasal airflow lasting $\geqslant 10 \mathrm{~s}$. Hypopnoea was defined as a decrease of $50 \%$ in oronasal airflow lasting $>10 \mathrm{~s}$ associated with a fall in arterial oxygen saturation $\left(\mathrm{SaO}_{2}\right)$ $>4 \%$ of the preceding baseline level. Mean night time $\mathrm{SaO}_{2}$, minimum $\mathrm{SaO}_{2}$ (lowest values recorded during sleep), desaturation index and percentage of time with $\mathrm{SaO}_{2}<90 \%$ on nocturnal oximetry were computed as indices of nocturnal oxygen saturation.

Twenty-four hour ABPM data were obtained using an oscillometric method (Spacelabs device, Model 90207; Redmond, Washington, USA). ${ }^{25}$ Blood pressure was measured every $30 \mathrm{~min}$ during the day (08.00 to $23.00 \mathrm{~h}$ ) and every 60 min during the night (23.00 to $08.00 \mathrm{~h}$ ) on a workday. An appropriate cuff was placed on the non-dominant arm. Patients were instructed to carry out their ordinary daily activities, to go to bed no later than $23.00 \mathrm{~h}$ and not to move their arm during recordings.

Echocardiography was performed in the supine and left lateral positions after a minimum rest period of 30 min using a high quality echocardiograph with $2.0-4.0 \mathrm{MHz}$ probes (Hewlett Packard Sonos 5500; Andover, Massachusetts, USA). Echocardiographic images were obtained in the parasternal long and short axes, apical two-chamber and four-chamber and subcostal views using two-dimensional, M-mode and Doppler echocardiographic techniques. The parameters were measured from at least three cardiac cycles. All echocardiograms were performed by the same experienced echocardiographer who was unaware of the subject group or the treatment assignment at each visit. Systolic function was assessed by left ventricular shortening fraction (LVSF) and left ventricular ejection fraction (LVEF) ${ }^{26} \mathrm{LVSF} \geqslant 28 \%$ and LVEF $\geqslant 50 \%$ were considered normal.

Forced spirometry was performed as previously described using a MasterScope system (Jaeger, Würtzburg, Germany) ${ }^{25}$

At each visit, subjects were requested to collect separate urine samples from $08.00 \mathrm{~h}$ until going to bed (day) and all urine during the night and the first sample after getting up in the morning (night). The urinary excretion of norepinephrine and epinephrine was determined as previously described. ${ }^{27}$

A specific enzyme immunoassay kit (Cayman Chemical, Ann Arbor, Michigan, USA) was used to measure 8-isoprostane 
Table 1 Baseline clinical and functional characteristics of study subjects

\begin{tabular}{|c|c|c|}
\hline & $\begin{array}{l}\text { Control subjects } \\
(\mathrm{n}=15)\end{array}$ & $\begin{array}{l}\text { OSAS patients } \\
(\mathrm{n}=31)\end{array}$ \\
\hline Age (years) & $48(10)$ & $52(13)$ \\
\hline BMI $\left(\mathrm{kg} / \mathrm{m}^{2}\right)$ & $28.7(4.7)$ & $30.5(4.0)$ \\
\hline Smokers (\%) & 27 & 35 \\
\hline Pack/years & $20(7)$ & $20(12)$ \\
\hline AHI (/h) & $3.7(3.3)$ & $43.8(27.0)^{*}$ \\
\hline Mean $\mathrm{SaO}_{2}(\%)$ & $94(2)$ & $91(6)+$ \\
\hline Minimum $\mathrm{SaO}_{2}(\%)$ & $85(5)$ & $72(15) \neq$ \\
\hline СТ90\% $\mathrm{SaO}_{2}$ & $0.0(0-0.05)$ & $6.3(2.0-29.8)^{*}$ \\
\hline Desaturation index (/h) & $4.0(3.0-7.5)$ & $41.2(18.9-63.3)^{*}$ \\
\hline FVC (\% predicted) & $99(16)$ & $105(17)$ \\
\hline $\mathrm{FEV}_{1}$ (\% predicted) & $108(16)$ & $111(15)$ \\
\hline $\mathrm{FEV}_{1} / \mathrm{FVC}(\%)$ & $88.2(3.6)$ & $85.8(7.2)$ \\
\hline \multicolumn{3}{|l|}{$\begin{array}{l}\text { Daytime ambulatory BP } \\
(\mathrm{mm} \mathrm{Hg})\end{array}$} \\
\hline Systolic & $122(9)$ & $126(10)$ \\
\hline Diastolic & $78(5)$ & $79(6)$ \\
\hline \multicolumn{3}{|l|}{$\begin{array}{l}\text { Night time ambulatory BP } \\
(\mathrm{mm} \mathrm{Hg})\end{array}$} \\
\hline Systolic & $110(10)$ & $117(11)$ \\
\hline Diastolic & $67(6)$ & $70(7)$ \\
\hline \multicolumn{3}{|l|}{ Norepinephrine $(\mu \mathrm{g} / \mathrm{g})$} \\
\hline Diurnal & $22.5(19.6-30.1)$ & $33.2(26.6-46.5)$ \\
\hline Nocturnal & $11.3(7.2-16.7)$ & $22.2(13.9-29.4) \dagger$ \\
\hline \multicolumn{3}{|l|}{ Epinephrine $(\mu \mathrm{g} / \mathrm{g})$} \\
\hline Diurnal & $6.9(3.4-10.3)$ & $7.2(4.0-11.8)$ \\
\hline Nocturnal & $3.4(2.2-4.9)$ & $6.3(3.8-9.9) \ddagger$ \\
\hline LVSF (\%) & $40.1(4.8)$ & $37.6(3.1)$ \\
\hline LVEF (\%) & $70.1(5.9)$ & $67.1(3.7)$ \\
\hline
\end{tabular}

${ }^{*} \mathrm{p}<0.001, \dagger \mathrm{p}<0.01, \mathrm{t} \mathrm{p}<0.05$ (Student $t$ test or Mann-Whitney $\mathrm{U}$ test). Values are mean (SD) or median (interquartile range) depending on the distribution. $\mathrm{AHI}$, apnoea-hypopnoea index; BMI, body mass index; BP, blood pressure; CT $90 \%$, percentage of total time study with $\mathrm{SaO}_{2}<90 \%$; $\mathrm{FEV}_{1}$, forced expiratory volume in $1 \mathrm{~s}$; FVC, forced vital capacity; LVEF, left ventricular ejection fraction; LVSF, left ventricular shortening fraction; OSAS, obstructive sleep apnoea syndrome; $\mathrm{SaO}_{2}$, oxygen saturation.

concentrations in plasma. The intra-assay and inter-assay variability were $5 \%$ and $7 \%$, respectively, and the detection limit of the assay was $5 \mathrm{pg} / \mathrm{ml}$.

Total nitrate and nitrite (NOx) were measured in plasma by capillary electrophoresis using a Beckman capillary electrophoresis system (P/ACE MDQ). Absorbance was read at $200 \mathrm{~nm}$ and nitrate concentration was determined using a $\mathrm{NaNO}_{3}$ standard. The lower detection limit was $10 \mu \mathrm{mol} / \mathrm{l}$ and the intra-assay and inter-assay variability were $5 \%$ and $8 \%$, respectively.

\section{Statistical analysis}

Values are expressed as mean (SD) or median (interquartile range, IOR) depending on their distribution. All statistical tests were two-sided. Comparisons between groups were performed using the Student $t$ test or the Mann-Whitney $U$ test. Categorical variables were compared using the $\chi^{2}$ test. Bivariate relationships between variables were determined by Pearson's or Spearman's correlation. To investigate the effect of CPAP therapy over time in patients with OSAS, repeated measures ANOVA was used with treatment (effective CPAP vs sham CPAP) as a within-subject factor and order of therapy as a between-subject factor. Whenever ANOVA results indicated the existence of significant differences between treatment conditions, post hoc multiple comparisons were performed with the Bonferroni test. A $p$ value of $<0.05$ was considered statistically significant. All analyses were performed using the SPSS Version 11.0 software (SPSS, Chicago, Illinois, USA).

\section{RESULTS}

\section{Characteristics of subjects}

Seven subjects refused to take part in the study and three were deemed ineligible for inclusion after initial assessments (one had diabetes mellitus and two because they had unknown mitral stenosis), so 31 patients with OSAS were randomised for inclusion in the study (fig 1).

Table 1 shows the main demographic and functional characteristics of all participants at baseline. Demographic data, smoking habits, spirometric results and ABPM results did not differ between patients with OSAS and healthy controls. As expected, sleep parameters were abnormal (and consistent with the diagnosis of OSAS) in patients but were normal in healthy subjects. Patients with OSAS had higher nocturnal levels of norepinephrine and epinephrine than control subjects but LVSF and LVEF were similar in both groups.

\section{Plasma concentrations of 8-isoprostane and total nitrate and nitrite (NOx)}

At recruitment, before treatment with CPAP, patients with OSAS had higher median (IOR) plasma levels of 8-isoprostane (42.5 (29.2-78.2) vs $20.0(12.5-52.5) \mathrm{pg} / \mathrm{ml}, \mathrm{p}=0.041)$ and lower plasma levels of NOx (264 (165-650) vs 590 (251-1465) $\mu \mathrm{mol} / \mathrm{l}$, $\mathrm{p}=0.022)$ than healthy subjects. There were no correlations between plasma levels of 8-isoprostane or NOx and sleep parameters.

\section{Effects of CPAP}

Six patients failed to complete the trial, leaving 25 patients for the final analysis. Two were excluded because, on average, they used CPAP at night for $<3.5 \mathrm{~h}$, while the remaining four patients were lost to follow-up (fig 1). The baseline anthropometric characteristics, smoking habit, lung function data, sleep study indices, sympathetic tone, ABPM or left ventricular systolic function of these six patients were not significantly different from those who completed the trial. The mean (SD) CPAP pressure value was 10 (2) $\mathrm{cm} \mathrm{H}_{2} \mathrm{O}$ and average nightly use of CPAP and sham CPAP was 6.2 (1.1) h and 6.3 (1.6) h, respectively.

BMI, ABPM and urinary catecholamines were not modified by CPAP (table 2). However, effective CPAP (but not sham CPAP) significantly decreased the plasma concentration of 8-isoprostane (from 38.5 (24.2-58.7) $\mathrm{pg} / \mathrm{ml}$ to 22.5 (16.2-35.3) $\mathrm{pg} / \mathrm{ml}$, $\mathrm{p}=0.0001)$ and increased the plasma concentration of $\mathrm{NOx}$ (from 280 (177-707) $\mu \mathrm{mol} / \mathrm{l}$ to 1373 (981-1517) $\mu \mathrm{mol} / \mathrm{l}$, $p=0.0001$, fig 2$)$. The decrease in 8-isoprostane concentration was similar in the OSAS subgroup treated with optimal CPAP and sham CPAP to that in the OSAS group treated with sham CPAP and optimal CPAP (18.3 (1.1-25.0) pg/ml vs 21.6 (4.0-25.6) pg/ml, $\mathrm{p}=0.276$ ). The increase in NOx concentration was also not affected by the treatment order (827 (563-974) $\mu \mathrm{mol} / \mathrm{l}$ vs 961 (630-1309) $\mu \mathrm{mol} / \mathrm{l}, \mathrm{p}=0.921)$. Values after CPAP therapy were not significantly different from those found in healthy subjects.

\section{DISCUSSION}

Our study provides two main findings of interest. First, the plasma concentration of 8-isoprostane is higher and that of NOx is lower in patients with OSAS carefully selected to exclude pulmonary and cardiovascular disease than in healthy 
Table 2 Effects of continuous positive airway pressure (CPAP) on blood pressure (BP) and urinary catecholamines, oxidative stress and nitrate and nitrite concentrations in patients with obstructive sleep apnoea syndrome

\begin{tabular}{llll}
\hline & Baseline & Sham CPAP & Therapeutic CPAP \\
\hline $\begin{array}{l}\text { Weight }(\mathrm{kg}) \\
\text { Daytime ambulatory BP }(\mathrm{mm} \mathrm{Hg})\end{array}$ & $88.8(14.5)$ & $88.6(15.2)$ & $88.4(15.8)$ \\
$\quad$ Systolic & $126(10)$ & $126(12)$ & $127(9)$ \\
$\quad$ Diastolic & $79(6)$ & $77(6)$ & $78(5)$ \\
Nighttime ambulatory BP (mm Hg) & $118(12)$ & $117(12)$ & $117(17)$ \\
$\quad$ Systolic & $70(8)$ & $70(6)$ & $69(9)$ \\
$\quad$ Diastolic & $32.9(26.6-47.5)$ & $32.2(25.3-41.8)$ & $32.8(21.1-37.5)$ \\
Norepinephrine $(\mu \mathrm{g} / \mathrm{g})$ & $20.6(15.4-32.7)$ & $16.4(13.9-27.5)$ & $19.8(14.8-29.4)$ \\
$\quad$ Diurnal & $7.0(3.9-11.5)$ & $7.2(4.7-11.2)$ & $7.3(4.9-10.5)$ \\
$\quad$ Nocturnal & $6.2(3.9-11.3)$ & $4.6(3.7-7.5)$ & $5.4(3.7-10.9)$ \\
Epinephrine $(\mu \mathrm{g} / \mathrm{g})$ & $38.5(24.2-58.7)$ & $42.1(34.7-50.1)$ & $22.5(16.2-35.3) \dagger+$ \\
$\quad$ Diurnal & $280(177-707)$ & $494(292-940)$ & $1373(981-1517) \dagger+$ \\
$\quad$ Nocturnal & & &
\end{tabular}

subjects matched for gender, age and BMI. Second, these abnormalities are normalised after 12 weeks of CPAP therapy.
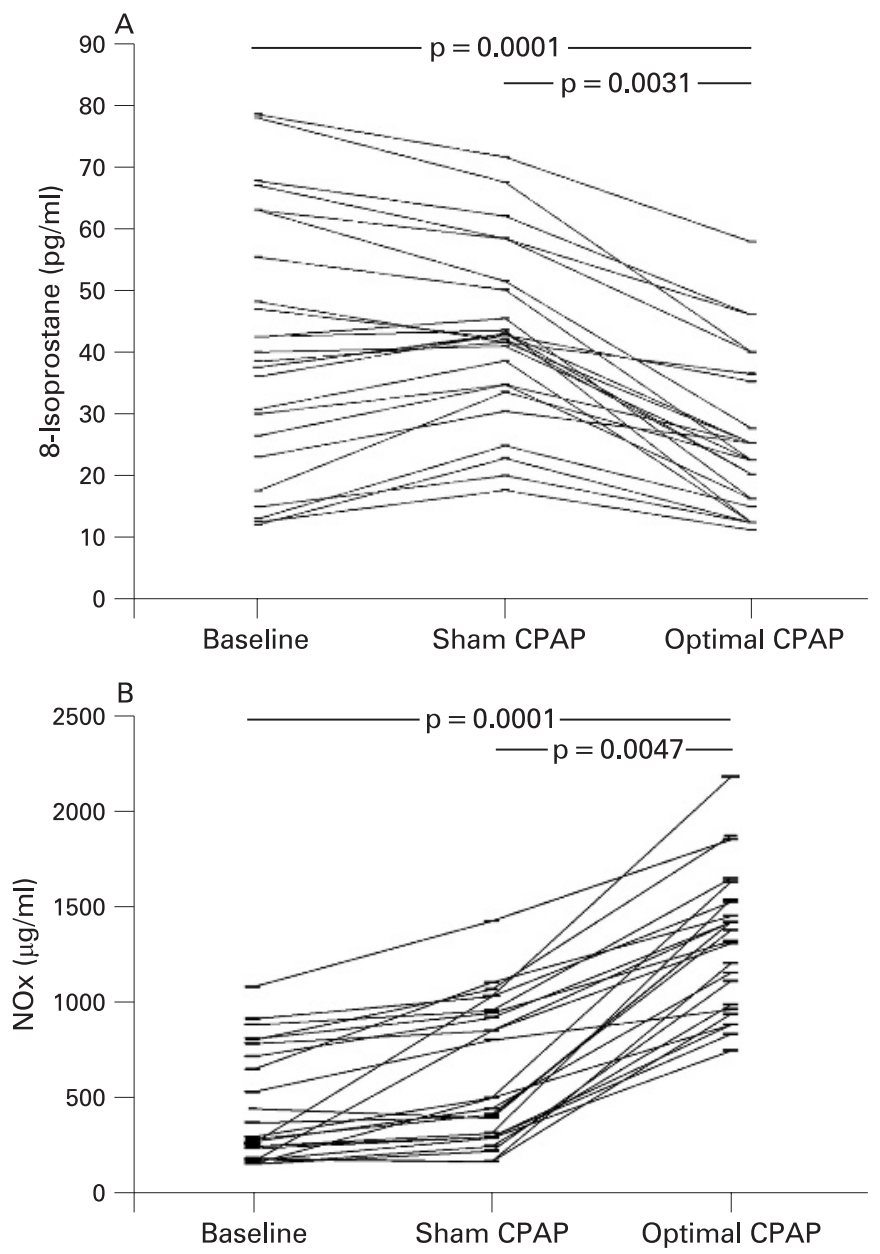

Figure 2 Individual plasma concentrations of (A) 8-isoprostane and (B) nitrate and nitrite (NOx) at baseline, after sham continuous positive airway pressure (CPAP) and optimal CPAP in patients with obstructive sleep apnoea syndrome.
Despite the fact that some previous studies have provided similar results, to the best of our knowledge ours is the first prospective randomised placebo controlled crossover study to evaluate oxidative stress and NO bioavailability in patients with OSAS and the effects of CPAP therapy on these parameters. Our results therefore provide a definite answer to some still unanswered questions in this field.

\section{Oxidative stress}

Many previous studies have identified an association between OSAS and cardiovascular disease. ${ }^{13}$ Oxidative stress is often proposed as a likely pathogenic mechanism. ${ }^{28} 29$ However, earlier studies of lipid peroxidation in OSAS provided conflicting results. Some of them could not find differences in the susceptibility to lipid peroxidation in these patients. ${ }^{15-17}$ This is best exemplified by the study of Svatikova et $a l^{16}$ who reported that the concentration of thiobarbituric acid-reactive substances, oxidised LDL autoantibodies and free isoprostane levels in 41 patients with severe OSAS without cardiovascular co-morbidity were similar to those of 35 healthy controls matched for BMI and age. However, they did not measure lung or left ventricular function, and controls were recruited from those who attended their sleep unit and had an AHI $<5 /$ h even though they had a relatively high sleep fragmentation index (22 (4)/h). Moreover, they employed a split-night protocol which is, in our opinion, unsuitable to investigate biomarker changes in these patients. ${ }^{16}$ On the other hand, several other studies reported abnormal lipid peroxidation in OSAS. ${ }^{10-14}$ For instance, Carpagnano et $a^{11}$ found higher levels of 8-isprostane in plasma and exhaled breath condensate in patients with OSAS than in controls, and Minoguchi et al demonstrated that the urinary levels of 8-isprostane in OSAS were related to the AHI. ${ }^{14}$ Isoprostanes are a complex family of compounds produced from arachidonic acid via a free radical catalysed mechanism. ${ }^{30}$ They are often used as clinical markers of lipid peroxidation in human diseases because of their stability and specificity. ${ }^{29}$ We found that patients with OSAS in whom pulmonary and cardiac co-morbidities were carefully excluded had higher 8-isoprostane plasma levels than healthy controls, and that CPAP therapy (but not treatment with sham CPAP) normalised these values. The results of studies investigating 
the effects of CPAP therapy on oxidative stress in OSAS have also yielded conflicting results. On the one hand, several uncontrolled studies showed that short-term, ${ }^{11}$ mediumterm $^{12} 1421$ and long-term ${ }^{10}{ }^{1320}$ CPAP reduces oxidative stress in patients with OSAS. In addition, Barceló et a l $^{18}$ found that treatment with CPAP for 1 year increased the plasma antioxidant status. In contrast, other groups failed to demonstrate that CPAP had any effect on oxidative stress and antioxidant capacity. ${ }^{16}{ }^{17}$ The differences between the studies may be due to the effects of several potential confounders and the fact that none of them was controlled by sham CPAP. In our study we sought to avoid these limitations by selecting participants (both patients with OSAS and controls) very carefully so that all of them were free of any other co-morbid disease and none was receiving medication either before or during the study period. Furthermore, we recruited into the study healthy subjects in whom subclinical pulmonary or cardiac disease was carefully excluded and, most importantly, we designed a placebo controlled crossover study which is the most powerful design for testing the efficacy of any therapeutic intervention. Under these circumstances, our results clearly show that effective CPAP therapy improves oxidative stress in patients with OSAS (table 2, fig 2). Taking into account all the above-mentioned arguments, we postulate that our results clearly show that OSAS produces oxidative stress and that this is treatable with CPAP.

\section{Nitrate and nitrite (NOx) deficiency}

Impaired nitric oxide (NO) release from endothelial cells is also regarded as an initiator and promoter of cardiovascular disease in patients with OSAS. Nitrate and nitrite (NOx) are stable derivatives of $\mathrm{NO}$ and their levels reflect overall $\mathrm{NO}$ production. ${ }^{31}$ Previous studies have shown that NO production is lower in patients with OSAS than in controls. ${ }^{7-9}{ }^{32}$ In keeping with these results, we also found that NOx levels were lower in OSAS than in an age- and BMI-matched control group. The mechanisms explaining this observation are unclear. Hypoxaemia is a likely candidate since it is known to suppress the expression of endothelial NO synthase, ${ }^{33}$ and previous studies have shown that NOx is inversely related to nocturnal desaturation ${ }^{89}$ and oxygen administration increases serum NOx in OSAS. ${ }^{9}$ On the other hand, previous studies have shown that effective CPAP therapy increases $\mathrm{NO}$ levels in OSAS. ${ }^{732}$ Furthermore, Lavie et a ${ }^{32}$ reported a significant decrease in circulating NO levels after CPAP withdrawal for just one night. Our study confirms these previous results using a highly robust design (randomised, placebo controlled, crossover trial). Thus, our results showed that treatment with CPAP for 3 months led to a significant improvement in NO metabolites compared with placebo.

\section{Strengths and potential limitations}

As discussed above, the main strengths of the study are the experimental design (randomised, placebo controlled, crossover trial) and the careful selection of patients and controls (in whom co-morbidities were carefully excluded). Yet, as in any study, there are some potential limitations that deserve comment. First, the sample size was relatively small. This was due to the difficulty of including only middle-aged patients with newly diagnosed OSAS who had no other diseases and were taking no cardiovascular medication. Second, because our study included only men, our results may not be directly applicable to women.

\section{CONCLUSIONS}

The results of this study show that OSAS causes oxidative stress and reduces NOx bioavailability, and that CPAP therapy normalises these biological abnormalities.

Funding: This research was partially supported by a grant from the Fondo de Investigación Sanitaria (FIS; exp 01/0278).

\section{Competing interests: None.}

Ethics approval: The study was approved by the Institutional Ethics Committee at the hospital and all subjects gave their written informed consent.

\section{REFERENCES}

1. Arias MA, Garcia-Rio F, Alonso-Fernandez A, et al. Obstructive sleep apnea syndrome affects left ventricular diastolic function: effects of nasal continuous positive airway pressure in men. Circulation 2005;112:375-83.

2. Laaban JP, Pascal-Sebaoun S, Bloch E, et al. Ventricular systolic dysfunction in patients with obstructive sleep apnea syndrome. Chest 2002;122:1133-8.

3. Marin JM, Carrizo SJ, Vicente E, et al. Long-term cardiovascular outcomes in men with obstructive sleep apnoea-hypopnoea with or without treatment with continuous positive airway pressure: an observational study. Lancet 2005;365:1046-53.

4. Nieto FJ, Young TB, Lind BK, et al. Association of sleep-disordered breathing, sleep apnea, and hypertension in a large community-based study. Sleep Heart Health Study. JAMA 2000;283:1829-36.

5. Resta 0, Foschino-Barbaro MP, Bonfitto $P$, et al. Prevalence and mechanisms of diurnal hypercapnia in a sample of morbidly obese subjects with obstructive sleep apnoea. Respir Med 2000;94:240-6.

6. Shahar E, Whitney CW, Redline S, et al. Sleep-disordered breathing and cardiovascular disease: cross-sectional results of the Sleep Heart Health Study. Am J Respir Crit Care Med 2001;163:19-25.

7. Ip MS, Lam B, Chan LY, et al. Circulating nitric oxide is suppressed in obstructive sleep apnea and is reversed by nasal continuous positive airway pressure. Am J Respir Crit Care Med 2000;162:2166-71.

8. Schulz R, Schmidt D, Blum A, et al. Decreased plasma levels of nitric oxide derivatives in obstructive sleep apnoea: response to CPAP therapy. Thorax 2000;55:1046-51.

9. Teramoto $\mathbf{S}$, Kume $\mathrm{H}$, Matsuse $\mathrm{T}$, et al. Oxygen administration improves the serum level of nitric oxide metabolites in patients with obstructive sleep apnea syndrome. Sleep Med 2003;4:403-7.

10. Barcelo A, Miralles C, Barbe F, et al. Abnormal lipid peroxidation in patients with sleep apnoea. Eur Respir J 2000;16:644-7.

11. Carpagnano GE, Kharitonov SA, Resta 0, et al. 8-Isoprostane, a marker of oxidative stress, is increased in exhaled breath condensate of patients with obstructive sleep apnea after night and is reduced by continuous positive airway pressure therapy. Chest 2003;124:1386-92.

12. Hernandez C, Abreu J, Abreu P, et al. Efectos del tratamiento con CPAP nasal en el estrés oxidativo en pacientes con síndrome de apnea del sueño. Arch Bronconeumol 2006:42:125-9.

13. Lavie L, Vishnevsky A, Lavie P. Evidence for lipid peroxidation in obstructive sleep apnea. Sleep 2004;27:123-8.

14. Minoguchi K, Yokoe T, Tanaka A, et al. Association between lipid peroxidation and inflammation in obstructive sleep apnoea. Eur Respir J 2006;28:378-85.

15. Ozturk L, Mansour B, Yuksel M, et al. Lipid peroxidation and osmotic fragility of red blood cells in sleep-apnea patients. Clin Chim Acta 2003;332:83-8.

16. Svatikova A, Wolk R, Lerman LO, et al. Oxidative stress in obstructive sleep apnoea. Eur Heart J 2005;26:2435-9.

17. Wali So, Bahammam AS, Massaeli $\mathrm{H}$, et al. Susceptibility of LDL to oxidative stress in obstructive sleep apnea. Sleep 1998;21:290-6.

18. Barcelo A, Barbe F, de la PM, et al. Antioxidant status in patients with sleep apnoea and impact of continuous positive airway pressure treatment. Eur Respir $J$ 2006;27:756-60.

19. Carpagnano GE, Kharitonov SA, Resta 0, et al. 8-Isoprostane, a marker of oxidative stress, is increased in exhaled breath condensate of patients with obstructive sleep apnea after night and is reduced by continuous positive airway pressure therapy. Chest 2003;124:1386-92.

20. Dyugovskaya L, Lavie P, Lavie L. Increased adhesion molecules expression and production of reactive oxygen species in leukocytes of sleep apnea patients. Am J Respir Crit Care Med 2002;165:934-9.

21. Schulz R, Mahmoudi S, Hattar K, et al. Enhanced release of superoxide from polymorphonuclear neutrophils in obstructive sleep apnea. Impact of continuous positive airway pressure therapy. Am J Respir Crit Care Med 2000;162:566-70.

22. Farre R, Hernandez L, Montserrat JM, et al. Sham continuous positive airway pressure for placebo-controlled studies in sleep apnoea. Lancet 1999;353:1154.

23. Masa JF, Jimenez A, Duran J, et al. Alternative methods of titrating continuous positive airway pressure: a large multicenter study. Am J Respir Crit Care Med 2004;170:1218-24.

24. Ballester E, Solans M, Vila X, et al. Evaluation of a portable respiratory recording device for detecting apnoeas and hypopnoeas in subjects from a general population Eur Respir J 2000;16:123-7. 
25. Garcia-Rio F, Pino JM, Alonso A, et al. White coat hypertension in patients with obstructive sleep apnea-hypopnea syndrome. Chest 2004;125:817-22.

26. Quinones MA, Waggoner AD, Reduto LA, et al. A new, simplified and accurate method for determining ejection fraction with two-dimensional echocardiography. Circulation 1981:64:744-53.

27. Alonso-Fernandez A, Garcia-Rio F, Arias MA, et al. Obstructive sleep apnoeahypoapnoea syndrome reversibly depresses cardiac response to exercise. Eur Heart J 2006;27:207-15

28. Ehara $\mathbf{S}$, Ueda $\mathrm{M}$, Naruko $\mathrm{T}$, et al. Elevated levels of oxidized low density lipoprotein show a positive relationship with the severity of acute coronary syndromes. Circulation 2001;103:1955-60.
29. Gross M, Steffes M, Jacobs DR, et al. Plasma F2-isoprostanes and coronary artery calcification: the CARDIA Study. Clin Chem 2005:51:125-31.

30. Morrow JD, Hill KE, Burk RF, et al. A series of prostaglandin F2-like compounds are produced in vivo in humans by a non-cyclooxygenase, free radical-catalyzed mechanism. Proc Natl Acad Sci U S A 1990;87:9383-7.

31. Viinikka L. Nitric oxide as a challenge for the clinical chemistry laboratory. Scand J Clin Lab Invest 1996:56:577-81.

32. Lavie L, Hefetz A, Luboshitzky R, et al. Plasma levels of nitric oxide and L-arginine in sleep apnea patients: effects of nCPAP treatment. J Mol Neurosci 2003:21:57-63.

33. McQuillan LP, Leung GK, Marsden PA, et al. Hypoxia inhibits expression of eNOS via transcriptional and posttranscriptional mechanisms. Am J Physiol 1994;267:H1921-7.

\section{ANSWER}

From the question on page 580

The MRI shows cor triatriatum (fig 1). This is a rare congenital abnormality accounting for $0.1 \%$ of all congenital cardiac malformations. ${ }^{1}$ It is caused by a failure of common pulmonary vein resorption during cardiogenesis. This leads to persistence of a diaphragm-like membrane dividing the left atrium. Communication between the chambers is via one or more orifices. The size of this communication determines the degree of obstruction to pulmonary venous return. Elevation in pulmonary venous pressure and pulmonary vascular resistance may cause pulmonary hypertension (PHT). ${ }^{2}$ As in this case, echocardiography may not reveal the left atrial membrane.

Normal pregnancy is characterised by a $45-50 \%$ increase in blood volume and cardiac output and a reduction in vascular resistance. ${ }^{3}$ In pulmonary arterial hypertension (PAH), which is an important cause of PHT, the stiff pulmonary circulation cannot accommodate the increased blood flow, which may cause the right ventricle to fail. A dilated right ventricle can, in turn, reduce left heart filling and hence lead to low cardiac output heart failure. ${ }^{4}$

Published case reports of PHT in pregnancy reveal that the maternal mortality rate is between $30 \%$ and $56 \%$ depending on the aetiology, although the true mortality may be higher. Fetal/ neonatal mortality is $10-12 \%$. Most women die in the postpartum period of treatment-resistant right heart failure. ${ }^{5}$

It is vital to establish the aetiology of PHT and not assume that all causes are related to PAH. In cases such as these, specific $\mathrm{PAH}$ therapies are unhelpful and may even be contraindicated.

Cardiac MRI may be particularly useful in pregnancy as it does not expose the mother or fetus to radiation and can help determine the aetiology and severity of the haemodynamic changes. ${ }^{6}$

Our patient had a forceps delivery under combined spinal/ epidural anaesthesia at 36 weeks gestation. She did not require any specific therapy for her PHT during pregnancy or

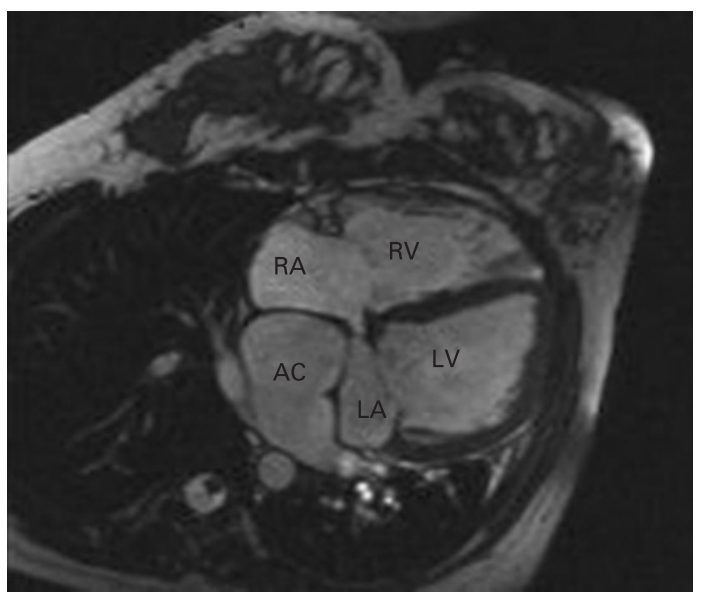

Figure $1 \mathrm{MRI}$ showing cor triatriatum. $A C$, antechamber; $L A$, left atrium; LV, left ventricle; $R A$, right atrium; $R V$, right ventricle.

postpartum. She has declined de-roofing surgery to correct the cor triatriatum. Mother and baby are doing well.

Thorax 2009;64:586. doi:10.1136/thx.2008.105353a

\section{REFERENCES}

1. Niwayama G. Cor triatriatum. Am Heart J 1960:59:291-317.

2. Van Praagh R, Corsini I. Cor triatriatum: pathologic anatomy and a consideration of morphogenesis based on 13 post-mortem cases and a study of normal development of the pulmonary vein and atrial septum in 83 human embryos. Am Heart J 1969;78:379-9.

3. Hunter $\mathbf{S}$, Robson S. Adaptation of the maternal heart in pregnancy. Br Heart $J$ 1992:68:540-3.

4. Smedstad K, Cramb R, Morison D. Pulmonary hypertension and pregnancy: a series of eight cases. Can J Anaesth 1994;93:428-39.

5. Weiss B, et al. Outcome of pulmonary vascular disease in pregnancy: a systematic overview from 1978 through 1996. J Am Coll Cardiol 1998;31:1650-7.

6. Saba TS, et al. Ventricular mass index using magnetic resonance imaging accurately estimates pulmonary artery pressure. Eur Respir J 2002;20:1519-24. 